\title{
Produção de beterraba fertilizada com jitirana em diferentes doses e tempos de incorporação ao solo
}

\author{
Maiele L. da Silva ${ }^{1}$, Francisco Bezerra N eto ${ }^{1}$, Paulo C. F. Linhares ${ }^{1}$, José R. de Sá ${ }^{1}$, \\ Jailma S. S. de Lima ${ }^{1} \&$ Aurélio P. Barros Júnior ${ }^{2}$
}

\begin{abstract}
RESUMO
Este trabalho foi conduzido no período de julho a novembro de 2009, na Fazenda Experimental Rafael Fernandes, da Universidade Federal Rural do Semi-Árido - UFERSA, Brasil, objetivando-se avaliar a produção da beterraba (Beta vulgaris L.) fertilizada com jitirana (M erremia aegyptia L.) sob diferentes doses e tempos de sua incorporação ao solo. 0 delineamento experimental adotado foi em blocos completamente casualizados e os tratamentos arranjados em esquema fatorial $4 \times 4+1$ com 3 repetições, com 72 plantas por parcela, sendo o primeiro fator constituído pelas doses de jitirana $(5,4 ; 8,8 ; 12$,2 e 15,6 tha-1 em base seca), o segundo pelos tempos de sua incorporação ao solo (0, 10, 20 e 30 dias após a semeadura - D AS) e o tratamento adicional com adubação de $80 \mathrm{tha}^{-1}$ de esterco bovino. A cultivar de beterraba plantada foi a Early W onder. A melhor performance produtiva da beterraba foi obtida na dose de $15,6 \mathrm{t}^{-1}$ de jitirana incorporada ao solo, no tempo 0 dia. Os indicadores econômicos na dose de 15,6 tha-1 no tempo de 0 dia foram superiores aos obtidos com o uso de $80 \mathrm{tha}^{-1}$ de esterco bovino. 0 cultivo da beterraba é viável agroeconomicamente com o uso da jitirana como adubo verde.
\end{abstract}

Palavras-chave: Beta vulgaris, Merremia aegyptia, adubação verde, eficiência produtiva

\section{Production of sugar beet fertilized with scarlet starglory at different doses and times of incorporation to soil}

\begin{abstract}
This study was conducted from July to November 2009, at U niversidade Federal Rural do Semi-Árido (U FERSA), Mossoró, RN, Brazil, to assess the production of sugar beet (Beta vulgaris L.) fertilized with scarlet starglory (M erremia aegyptia L.) at different doses and times of soil incorporation. The experimental design was a randomized complete block with treatments arranged in a $4 \times 4+1$ factorial, with three replicates and 72 plants per plot, where the first factor consisted of the doses of scarlet starglory $(5.4,8.8$, 12.2 and 15. $6 \mathrm{t} \mathrm{ha}^{-1}$ on dry basis), the second one by the times of soil incorporation $(0,10,20$, and 30 days after sowing - DAS), and additional treatment with $80 \mathrm{t} \mathrm{ha}^{-1}$ of cattle manure. The sugar beet cultivar grown was Early Wonder. The best productive performance for sugar beet was obtained in the dose of $15.6 \mathrm{t} \mathrm{ha}^{-1}$ of scarlet starglory incorporated into the soil at time 0 day. Economic indicators in the dose of scarlet starglory of $15.6 \mathrm{t} \mathrm{ha}^{-1}$ at time 0 day of its incorporation into the soil were higher than those obtained with the use of $80 \mathrm{t} \mathrm{ha}^{-1}$ of cattle manure. The cultivation of sugar beet is agro-economically viable with the use of scarlet starglory as green manure.
\end{abstract}

Key words: Beta vulgaris, Merremia aegyptia, green manure, productive efficiency 


\section{INTRODUÇÃO}

Uma das principais hortaliças cultivadas no Brasil é a beterraba (Beta vulgaris L.), ocupando a 13ª posição, em termos de valor econômico de sua produção (Souza et al., 2003). A estimativa da área plantada no País está em torno de 10.000 hectares, com produtividade média oscilando entre 20 e 35 $\mathrm{t} \mathrm{ha}^{-1}$ (Resende \& Cordeiro, 2007). Esta hortaliça tem sido cultivada de forma convencional, com uso intensivo de fertilizantes minerais e agrotóxicos, buscando-se aumentar a produtividade e a qualidade. No entanto, o uso intensivo desses produtos tem afetado o meio ambiente além de tornar o sistema de produção mais caro (Oliveira, 2009). Novas alternativas têm surgido, como o sistema orgânico de produção, para minimizar ou eliminar o uso de fertilizantes minerais e de agrotóxicos.

Estercos animais, compostos orgânicos e resíduos agroindustriais, são amplamente utilizados no sistema orgânico de hortaliças mas não suficientes para alicerçar e exponenciar a agricultura orgânica mundial (Almeida et al., 2008; Khatouniam, 2001). Além disso, nem sempre estão disponíveis dentro ou próximo à unidade de produção e se tornam alvo de uma série de restrições técnicas em relação ao seu emprego na agricultura orgânica.

A utilização de insumos alternativos, como a adubação verde, pode permitir diminuição das doses de esterco aplicadas e contribuir para reposição das reservas de $\mathrm{N}$ no solo (Castro et al., 2004). Entre os efeitos benéficos proporcionados pela adubação verde se destaca a melhoria das características físicas, favorecendo a agregação do solo, maior retenção de água e prevenindo, assim, a erosão e uma liberação maior de nutrientes com decomposição dos resíduos (Nascimento \& Mattos, 2007). De acordo com Fontanétti et al. (2004), a adubação verde reduz as amplitudes diárias da variação térmica e hídrica na camada superficial do solo, proporciona a formação e estabilização de agregados, melhorando as condições de aeração, infiltração e retenção de umidade. Além desses efeitos a adubação verde tem sido usada como estratégia para minimizar os impactos provocados pelo uso intensivo do solo, aliando proteção e adubação (Silveira et al., 2005). Os efeitos dessa técnica são bastante variáveis, dependendo da espécie utilizada, do manejo dado à biomassa, da época de plantio, do corte do adubo verde, do tempo de permanência dos resíduos no solo, das condições locais e da interação entre esses fatores (Alcântara et al., 2000).

Trabalhos têm evidenciado o efeito positivo de diferentes espécies utilizadas como adubos verdes em diversas hortaliças. Segundo Calegari (2002) e Fageria \& Santos (2007) os adubos verdes, como a mucuna-preta (Mucuna aterrima), a crotalária (Crotalaria juncea L.), guandu-anão (Cajanus cajan) e leucena (Leucena leucocephala), são promissores para esta prática devido à produção de massa verde e riqueza em $\mathrm{N}$.

Outra opção entre as plantas utilizadas como adubação verde é o uso de espécies espontâneas. Referidas espécies podem promover não apenas os mesmos efeitos que as plantas cultivadas para a adubação verde mas também maior ciclagem de nutrientes favorecendo, daí, a biota do solo e contribuindo, de forma positiva, para os sucessivos cultivos agrícolas (Favero et al., 2000). Entre essas espécies se encontra a jitirana (Merremia aegyptia L.), pertencente à família das convolvuláceas, comumente conhecida como jitirana, jetirana e jetirana-de-batata e corda de viola. É uma trepadeira anual, herbácea, possui caule cilíndrico, sulcado e glabroso ou, mais comumente, com pubescência hisurta, amarelada e folhas alternas membranáceas, com cinco segmentos, palmadas, com face ventral e dorsal esparsamente pilosa (Falcão, 1954).

Algumas pesquisas têm sido realizadas com a jitirana como adubo verde, em diferentes hortaliças, tais como o rabanete (Linhares et al., 2009a) a alface (Linhares et al. 2009b) e a rúcula (Linhares et al., 2008) razão por que se objetivou, com este trabalho, avaliar a produção de beterraba fertilizada com jitirana sob diferentes doses e tempos de incorporação ao solo.

\section{MATERIAL E MÉTODOS}

O estudo foi conduzido na Fazenda Experimental Rafael Fernandes, da Universidade Federal Rural do Semi-Árido (UFERSA), localizada no distrito de Alagoinha, distante $20 \mathrm{~km}$ da sede do município de Mossoró ( $5^{\circ} 11^{\prime} \mathrm{S}$ e $37^{\circ} 20^{\prime} \mathrm{W}, 18 \mathrm{~m}$ de altitude) no período de agosto a novembro de 2009, em solo classificado como Latossolo Vermelho Amarelo Argissólico franco arenoso (EMBRAPA, 2006). O clima nessa região, pela classificação de Köppen, é BsWh, ou seja, seco, muito quente e com estação chuvosa no verão, temperatura média máxima entre 32,1 e $34,5^{\circ} \mathrm{C}$ e média mínima entre 21,3 e $23,7^{\circ} \mathrm{C}$, sendo junho e julho os meses mais frios e a precipitação média anual em torno de 825 mm (Carmo Filho \& Oliveira, 1989). Da área experimental foram retiradas amostras de solo, encaminhadas para serem processadas e analisadas no Laboratório de Química e Fertilidade de Solos da UFERSA, fornecendo os seguintes valores: $\mathrm{pH}$ (água) $=6,00 ; \mathrm{Ca}=2,00 \mathrm{cmol}_{\mathrm{c}} \mathrm{dm}^{-3} ; \mathrm{Mg}=0,50$ $\mathrm{cmol}_{\mathrm{c}} \mathrm{dm}^{-3} ; \mathrm{Al}=0,00 \mathrm{cmol}_{\mathrm{c}} \mathrm{dm}^{-3} ; \mathrm{K}=44,8 \mathrm{mg} \mathrm{dm}^{-3} ; \mathrm{Na}=44,7$ $\mathrm{mg} \mathrm{dm}{ }^{-3} ; \mathrm{P}=7,7 \mathrm{mg} \mathrm{dm}^{-3}$.

O delineamento experimental adotado foi de blocos completamente casualizados, com os tratamentos arranjados em esquema fatorial 4 x $4+1$ com 3 repetições com 72 plantas por parcela. Os tratamentos consistiram da combinação de quatro doses de jitirana incorporadas ao solo $(5,4 ; 8,8 ; 12,8 \mathrm{e}$ $15,6 \mathrm{t} \mathrm{ha}^{-1} \mathrm{em}$ base seca) com quatro tempos de sua incorporação ao solo $(0 ; 10 ; 20$ e 30 dias após a semeadura - DAS) mais a testemunha de $80 \mathrm{t} \mathrm{ha}^{-1}$ de esterco bovino (Marques et al., 2010).

Cada parcela constou de seis fileiras de plantas, sendo as linhas laterais e as plantas de cabeceira de cada linha da área útil, consideradas bordadura. As parcelas tinham área total de $1,44 \mathrm{~m}^{2}$ eárea útil de $0,80 \mathrm{~m}^{2}$. O espaçamento foi de $0,20 \times 0,10 \mathrm{~m}$. A cultivar de beterraba plantada foi a "Early Wonder", recomendada para as condições semiáridas do nordeste brasileiro.

O preparo do solo da área experimental consistiu de uma gradagem seguida de levantamento dos canteiros e de uma solarização de 45 dias, para reduzir a população de fitopatógenos do solo. A jitirana utilizada foi coletada em uma área de aproximadamente 2,0 ha, completamente ocupada com jitirana, no início do período chuvoso. Após a colheita as plantas 
foram trituradas em máquina forrageira convencional obtendose, então, partículas de 2,0 a 3,0 cm, que foram secadas ao sol, até atingir o teor de umidade de $10 \%$ e analisadas, após o que se obtiveram os seguintes resultados: $\mathrm{N}=24,6 \mathrm{~g} \mathrm{~kg}^{-1} ; \mathrm{P}=10,5$ $\mathrm{g} \mathrm{kg}^{-1}$ e $\mathrm{K}=10,3 \mathrm{~g} \mathrm{~kg}^{-1}$.

Inicialmente foram incorporados $20 \%$ da jitirana em todas as parcelas, exceto na parcela proveniente de esterco bovino. Durante a decomposição irrigações diárias foram realizadas em dois turnos com a finalidade de favorecer a atividade microbiana do solo no processo de decomposição; 15 dias depois fez-se a incorporação de $80 \%$ do material nas parcelas referentes ao tempo de 0 dia realizando-se, então, a semeadura; decorridos dez dias, realizou-se a incorporação entre linhas nas parcelas referentes ao tempo de 10 dias e o mesmo ocorreu para as incorporações das parcelas dos tempos de 20 e 30 dias após o plantio.

A semeadura direta foi realizada no dia 09 de setembro de 2009, em covas de aproximadamente $3 \mathrm{~cm}$ de profundidade, colocando-se cinco a sete sementes por cova, e o desbaste foi feito aos 14 dias após o plantio deixando-se apenas uma planta por cova.

As irrigações foram efetuadas por microaspersão, com turno de rega diária parcelada em duas aplicações (manhã e tarde) fornecendo-se uma lâmina de água de aproximadamente $8 \mathrm{~mm}$ $\mathrm{d}^{-1}$; como tratos culturais foram realizadas duas capinas, manualmente, e uma amontoa. A colheita foi realizada no dia 17 de novembro, quando as plantas tinham as folhas novas arqueadas e as velhas amareladas.

Avaliaram-se as seguintes características: altura de plantas (determinada em uma amostra de quinze plantas retiradas aleatoriamente da área útil, através de uma régua, a partir do nível do solo até a extremidade da folha mais alta e expressa em centímetro); rendimento de massa fresca da parte aérea (determinado pela massa fresca da parte aérea de todas as plantas da área útil da parcela e expresso em $\mathrm{t} \mathrm{ha}^{-1}$ ); rendimento de massa seca da parte aérea (tomado em amostra de quinze plantas na qual se determinou a massa seca em estufa com circulação forçada de ar em temperatura $65^{\circ} \mathrm{C}$, até atingir peso constante, e expresso em $\mathrm{t} \mathrm{ha}^{-1}$ ); produtividade comercial de raízes (determinada a partir da massa da matéria fresca das raízes das plantas da área útil, livres de rachadura, bifurcações, nematóides e danos mecânicos, expressa em tha ${ }^{-1}$ ); rendimento de massa seca de raízes (tomado em amostra de quinze plantas na qual se determinou a massa seca, em estufa com circulação forçada de ar em temperatura $65^{\circ} \mathrm{C}$, até atingir peso constante, e expresso em $\mathrm{t} \mathrm{ha}^{-1}$ ) e a produtividade classificada de raízes, determinada através da classificação do diâmetro das raízes (DR) em extra (DR: $\geq 4 \mathrm{e}<5 \mathrm{~cm}$ ); extra A(DR: $\geq 5 \mathrm{e}<6 \mathrm{~cm}$ ); extra AA (DR: $\geq 6$ e $<7 \mathrm{~cm}$ ) e graúdas (DR: $>7$ ), sendo consideradas refugo todas as raízes danificadas, rachadas, bifurcadas e menores que $4 \mathrm{~cm}$ de diâmetro (Horta et al., 2001).

Realizaram-se análises de variância para as características avaliadas, através do aplicativo software SISVAR 3.01 (Ferreira, 2000). O procedimento de ajustamento de curvas de resposta para os fatores-tratamento foi realizado através do software Table Curve (Jandel Scientific, 1991). O teste de Student foi utilizado para comparar a média entre o tratamento adicional e a média dos tratamentos provenientes do fatorial.

\section{RESULTADOS E DISCUSSÃO}

Não houve interação significativa entre as doses de jitirana incorporadas ao solo e seus tempos de incorporação, para nenhuma das características avaliadas na beterraba (Figuras 1 a 6), significando que o comportamento das características avaliadas na beterraba em função das doses de jitirana incorporadas ao solo, foi semelhante em cada tempo de incorporação da jitirana ao solo e vice-versa.

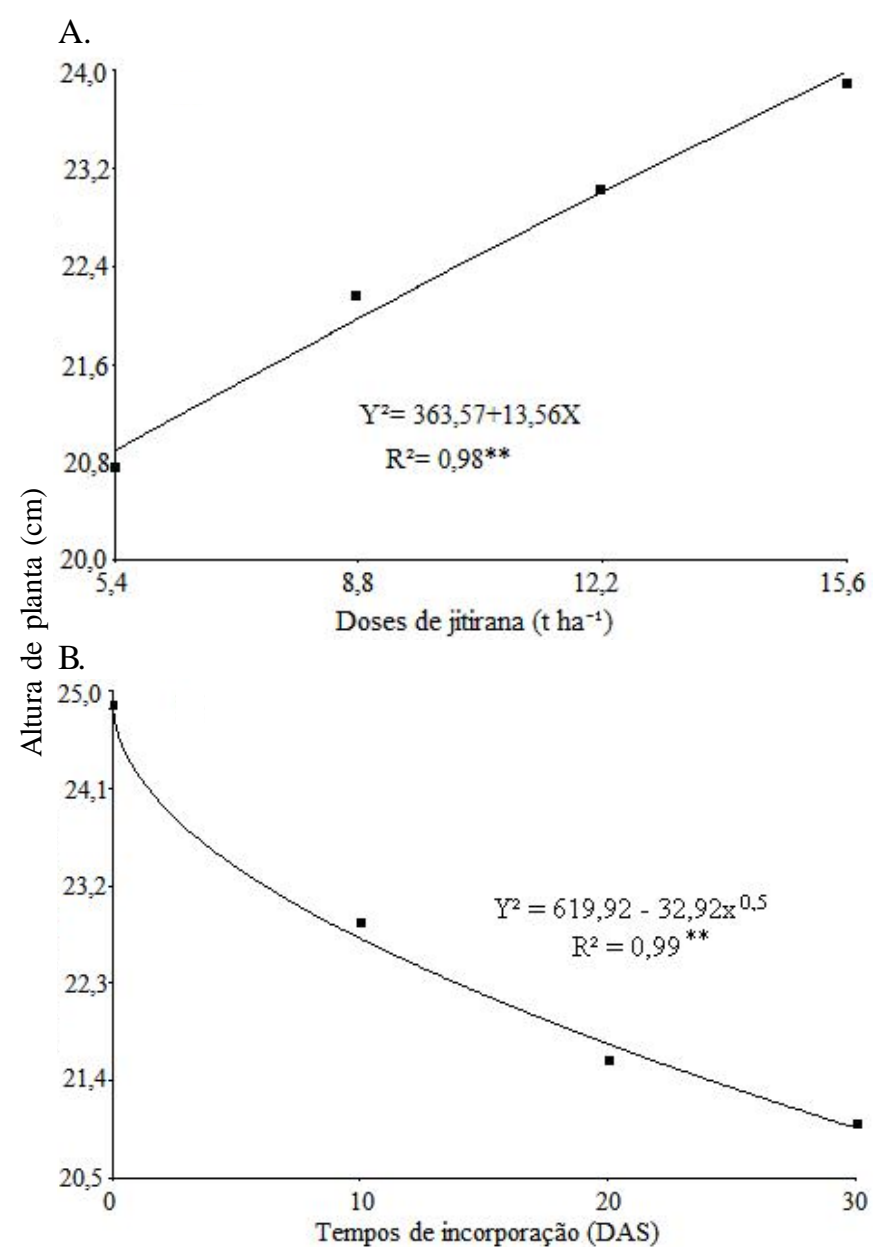

Figura 1. Altura de plantas de beterraba em função de doses de jitirana $(A)$ e de seus tempos de incorporação ao solo (B)

Uma resposta crescente na altura de plantas de beterraba foi observada em função das doses de jitirana incorporadas ao solo, em que a altura máxima de $23,9 \mathrm{~cm}$ foi alcançada na quantidade de 15,6 tha ${ }^{-1}$. O acréscimo entre a menor $\left(5,4 \mathrm{tha}^{-1}\right)$ e a maior $\left(15,6 \mathrm{t} \mathrm{ha}^{-1}\right)$ dose de jitirana, foi da ordem de $3 \mathrm{~cm}$ (Figura 1A). Trabalhos realizados por Alves et al. (2008) avaliando o desenvolvimento e o estado nutricional da beterraba em função da omissão de nutrientes, sinalizam uma altura média de plantas de $40,5 \mathrm{~cm}$ no tratamento com todos os nutrientes, porém no tratamento com ausência de $\mathrm{N}$ este resultado decaiu mais de $70 \%$ na altura de plantas da beterraba.

Por outro lado, a resposta da altura da beterraba foi decrescente nos tempos de incorporação da jitirana ao solo. Este decréscimo entre o tempo de 0 dia e de 30 dias da 
incorporação, foi da ordem de 3,3 cm (Figura 1B), resultado que adveio da baixa relação $\mathrm{C} / \mathrm{N}$ do adubo verde incorporado (18/1), influenciando na mineralização e disponibilidade de $\mathrm{N}$ no tempo em que a cultura necessitava deste nutriente para $\mathrm{o}$ seu desenvolvimento.

Para o rendimento de massa fresca da parte aérea observouse uma resposta crescente, em função das doses crescentes de jitirana incorporadas ao solo, em que o maior valor de rendimento $\left(9,03 \mathrm{tha}^{-1}\right)$ foi obtido na quantidade de jitirana de $15,6 \mathrm{t} \mathrm{ha}^{-1}$, correspondendo a um acréscimo de 22,36\% (Figura 2A). Resposta crescente de rendimento de massa fresca também foi observada em beterraba de mesa, em função da dose de N, por Aquino et al. (2006) e Trani et al. (2005). Este tipo de resposta se deve à maior quantidade de $\mathrm{N}$ encontrado na maior dose de jitirana incorporada ao solo. De acordo com Filgueira (2003) o $\mathrm{N}$ favorece o crescimento vegetativo de hortaliças.

Resposta decrescente foi constatada no rendimento de massa fresca da parte aérea da beterraba, em função dos tempos de incorporação da jitirana ao solo com rendimento máximo de $10,18 \mathrm{t} \mathrm{ha}^{-1}$ no tempo de 0 dia da incorporação(Figura 2B). Este decréscimo entre o tempo de 0 dia e de 30 dias da incorporação, foi da ordem de 27,7\%; no entanto, resultado diferente foi observado por Linhares et al. (2009a) estudando a cultura do

\section{A.}
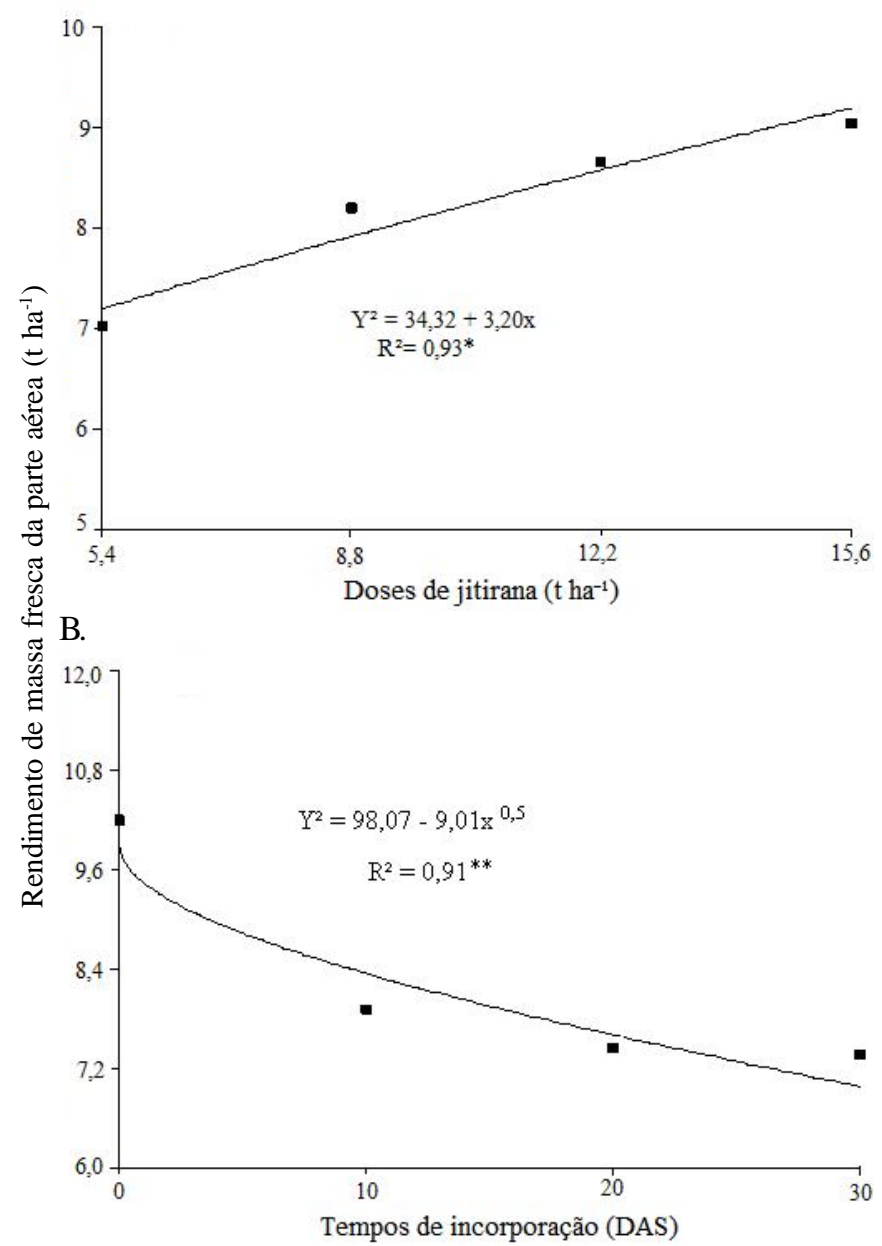

Figura 2. Rendimento de massa fresca da parte aérea de beterraba em função de doses de jitirana $(A)$ e de seus tempos de incorporação ao solo (B) rabanete em diferentes tempos de incorporação da jitirana ao solo.

Resposta crescente foi observada para o rendimento de massa seca da parte aérea de beterraba em função das doses crescentes de jitirana incorporadas ao solo, quando o maior valor de rendimento $\left(1,24 \mathrm{tha}^{-1}\right)$ foi observado na dose de jitirana de 15,6 tha-1, correspondendo a um acréscimo de $35 \%$ (Figura 3A). Resposta crescente também foi constatada em cenoura adubada com jitirana após a semeadura, por Oliveira (2009).

Outrossim, resposta decrescente foi observada no rendimento de massa seca da parte aérea em função dos tempos de incorporação da jitirana ao solo, com o rendimento máximo de 1,31 tha-1 de massa seca da parte aérea no tempo de 0 dia da incorporação (Figura 3B). Este decréscimo entre o tempo de 0 dia e de 30 dias da incorporação, foi da ordem de $29 \%$ de rendimento de massa seca da parte aérea; resultado diferente foi observado por Oliveira (2009) estudando a cultura da cenoura em diferentes tempos de incorporação da jitirana ao solo.

Para a produtividade comercial de raízes de beterraba observou-se resposta crescente em função das doses de jitirana incorporadas ao solo, com maior produtividade comercial de

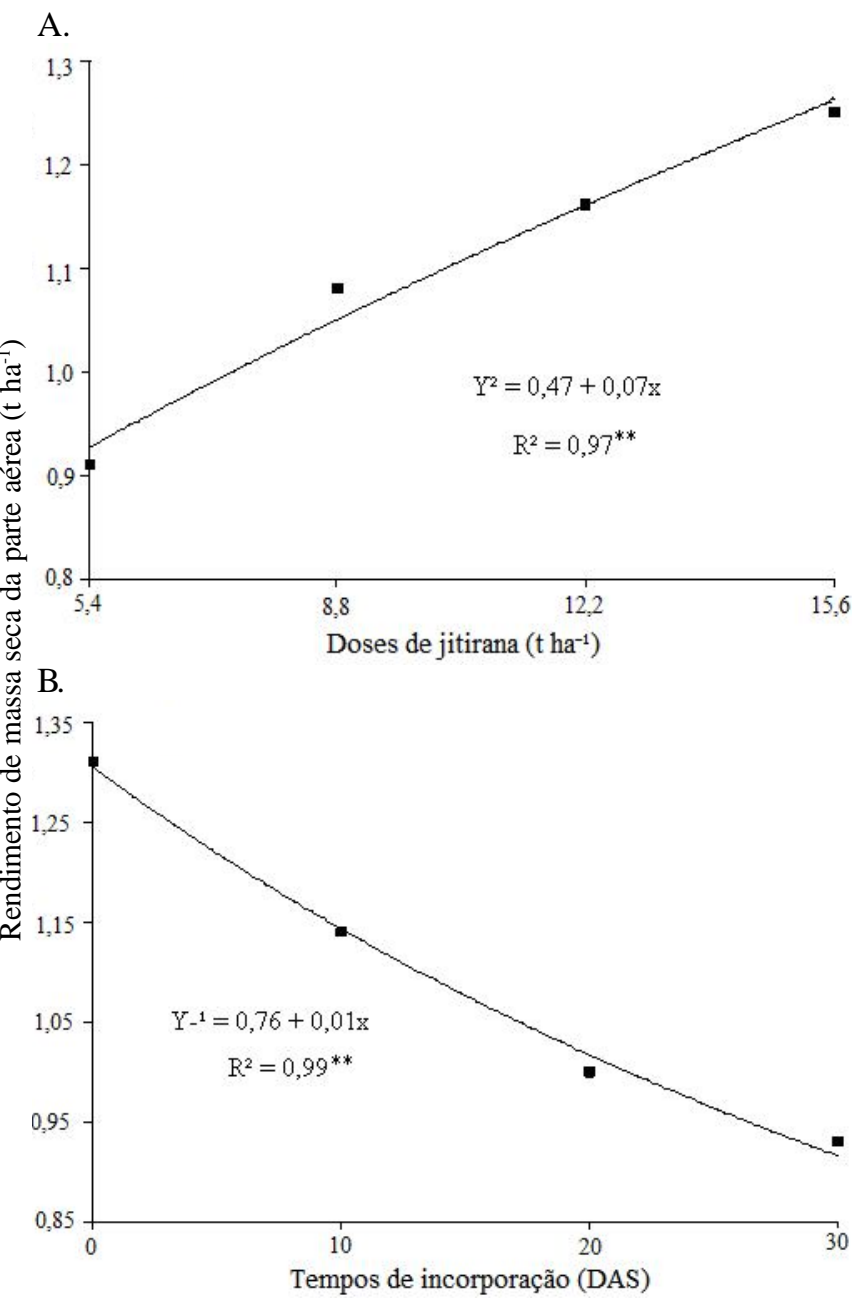

Figura 3. Rendimento de massa seca da parte aérea de beterraba em função de doses de jitirana (A) e de seus tempos de incorporação ao solo (B) 
9,80 t ha-1 obtidas na dose de 15,6 t ha ${ }^{-1}$ (Figura 4A). Esta produtividade difere da encontrada por Alves et al. (2004), avaliando hortaliças orgânicas após a incorporação de biomassa de guandu, com produtividade comercial de 22,9 t ha-1 de beterraba na presença de faixa de guandu incorporada. Os baixos valores de produtividade comercial de raízes de beterraba podem ser explicados pelas doses de adubo verde incorporadas ao solo, observando-se que não houve um ponto máximo com consequente diminuição, até a quantidade mais elevada testada.

Em relação ao tempo de incorporação constatou-se decréscimo da ordem de $65,8 \%$ com a produtividade comercial máxima de 14,93 tha ${ }^{-1}$ obtida no tempo de 0 dia da incorporação da jitirana (Figura 4B). Este tipo de resposta pode ter sido devido à época de maior exigência da beterraba por nutrientes se concentrar ao redor dos 40 a 60 dias. Segundo Grangeiro et al. (2007) a exigência da beterraba por $\mathrm{N}$ está no período de 50 a 60 dias e por $\mathrm{K}$ de 30 a 40 dias após a semeadura.

No rendimento de massa seca de raízes observou-se uma resposta crescente em função das doses de jitirana incorporadas ao solo. O rendimento máximo $\left(2,14 \mathrm{t} \mathrm{ha}^{-1}\right)$ foi constatado quando se aplicaram 15,6 $\mathrm{t} \mathrm{ha}^{-1}$ de jitirana, o que correspondeu a um acréscimo da ordem de 33,6\% em relação à menor quantidade (5,4 t ha-1) (Figura 5A). Este tipo de resposta

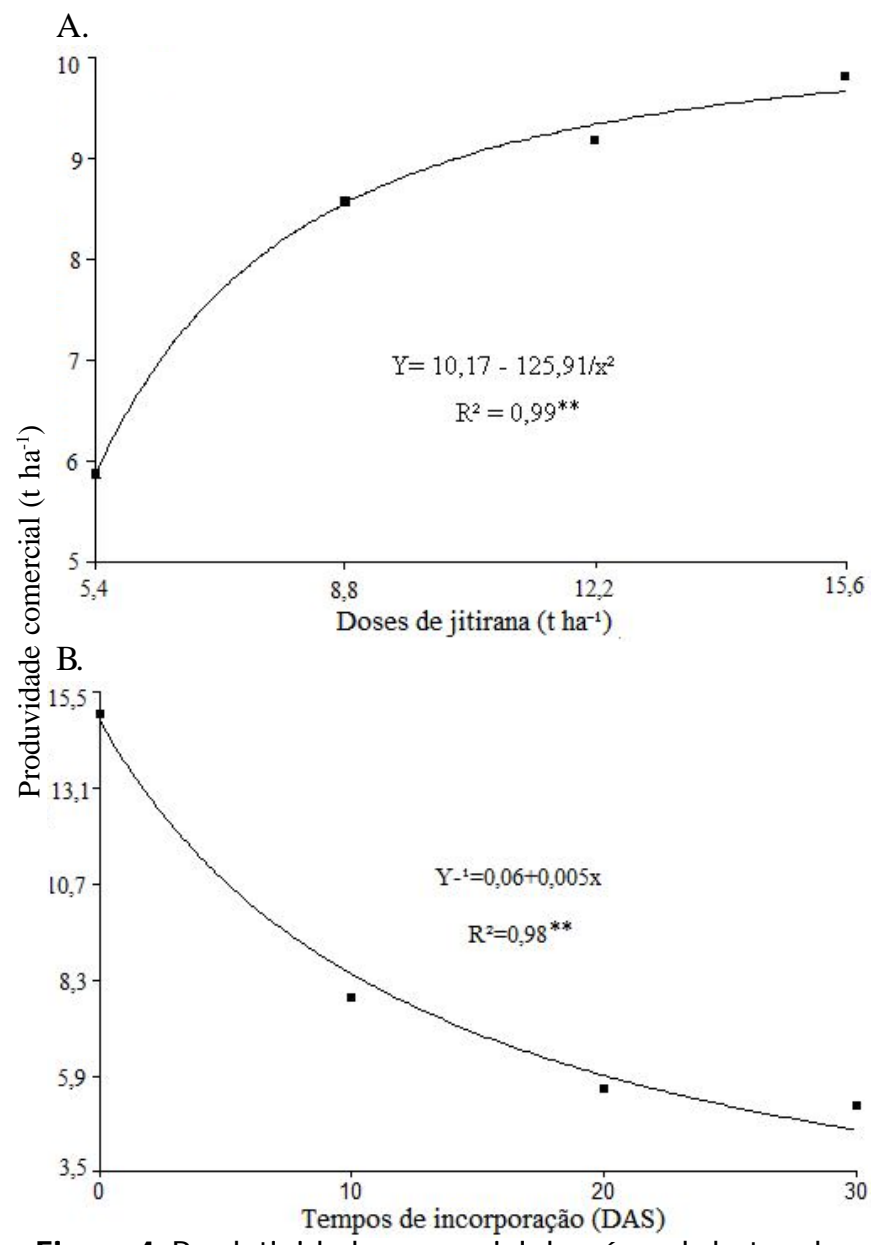

Figura 4. Produtividade comercial de raízes de beterraba em função de doses de jitirana $(A)$ e de seus tempos de incorporação ao solo (B)
A.

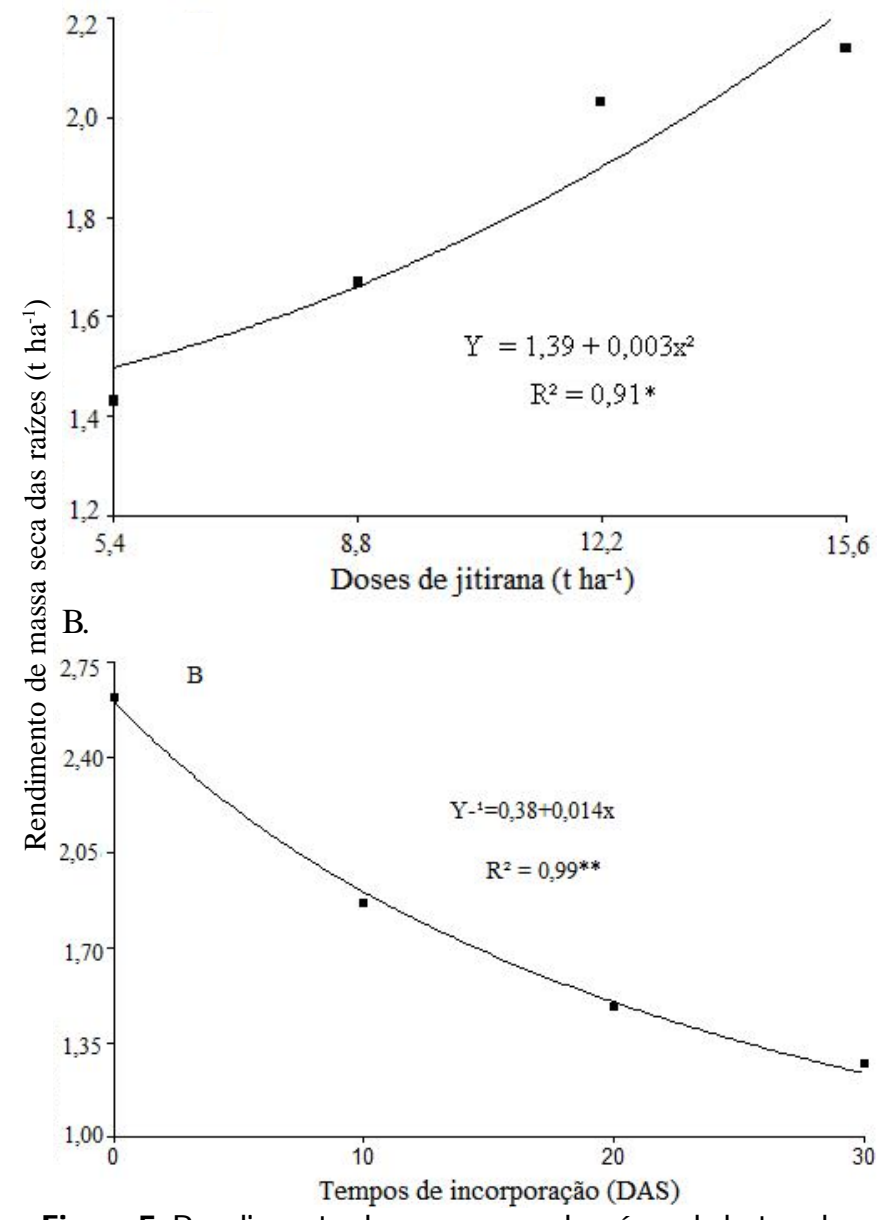

Figura 5. Rendimento de massa seca de raízes de beterraba em função de doses de jitirana (A) e de seus tempos de incorporação ao solo (B)

foi semelhante ao observado por Aquino et al. (2006), ao obterem maior rendimento de massa seca de raízes de beterraba na maior dose de N. Oliveira et al. (2009) observaram que as doses de jitirana não influenciaram os rendimentos de massa seca da cenoura.

Para os tempos de incorporação da jitirana ao solo foi constatada uma resposta decrescente no rendimento de massa seca de raízes de beterraba, com decréscimo da ordem de 51,5\%, no rendimento entre o tempo de 0 dia e de 30 dias da incorporação da jitirana (Figura 5B). Linhares et al. (2009a), avaliando a cultura do rabanete adubado com jitirana, mencionam maior rendimento de massa seca de raízes no tempo de 28 dias da incorporação.

Para a porcentagem de raízes extra de beterraba, não foi possível ajustar nenhuma equação de regressão em função das doses de jitirana incorporadas ao solo, observando-se uma porcentagem de raízes extra de beterraba de 27,25 e 30,14\% nas doses de jitirana de 5,4 te 15,6 ha-1 (Figura 6A).

Uma resposta decrescente na porcentagem de raízes extra foi observada em função dos tempos de incorporação de jitirana, com decréscimo da ordem de 5,5\% entre o tempo de 0 dia e 30 dias (Figura 6B).

Para a porcentagem de raízes extra A não foi possível ajustar qualquer equação de regressão em função das doses de jitirana 

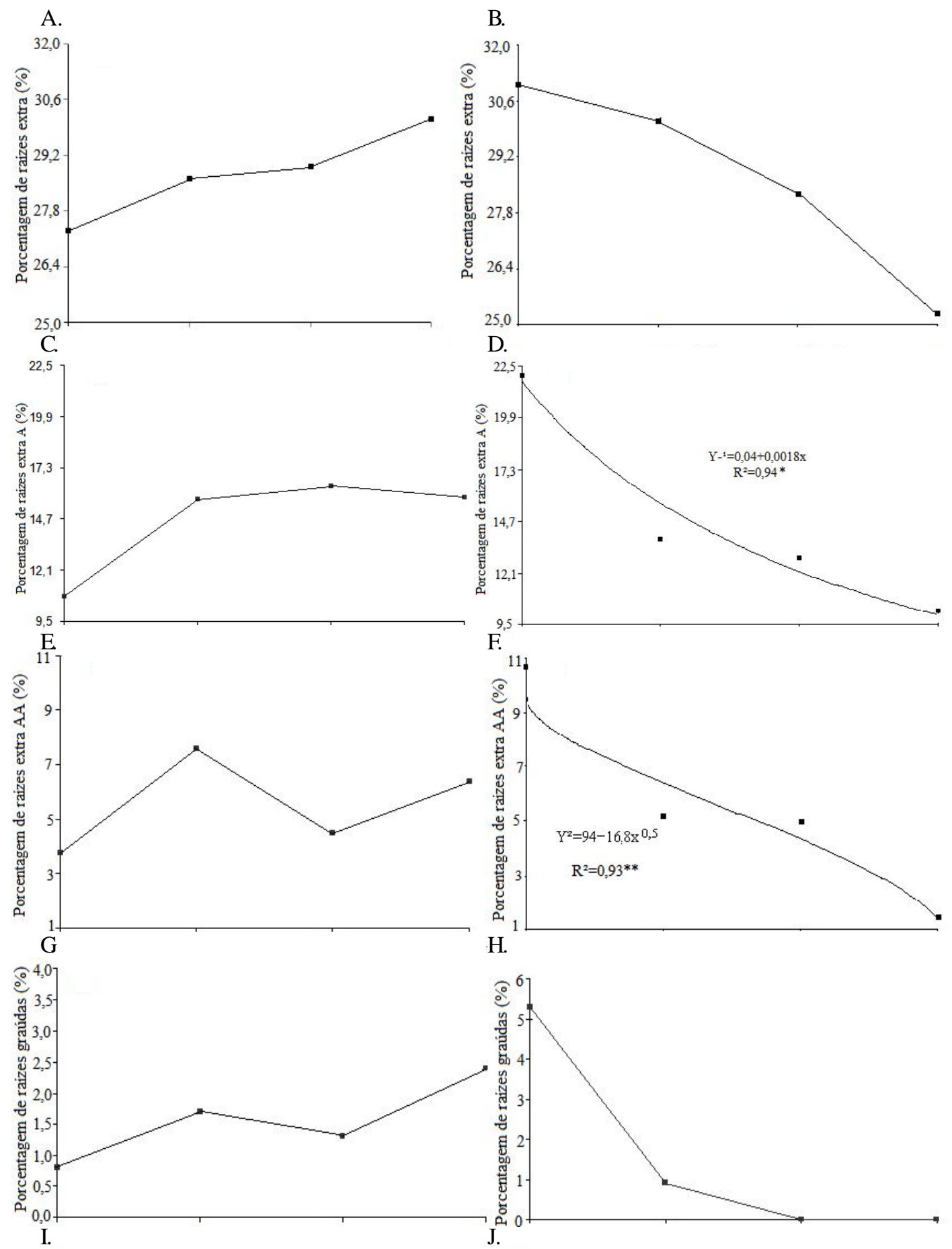

H.
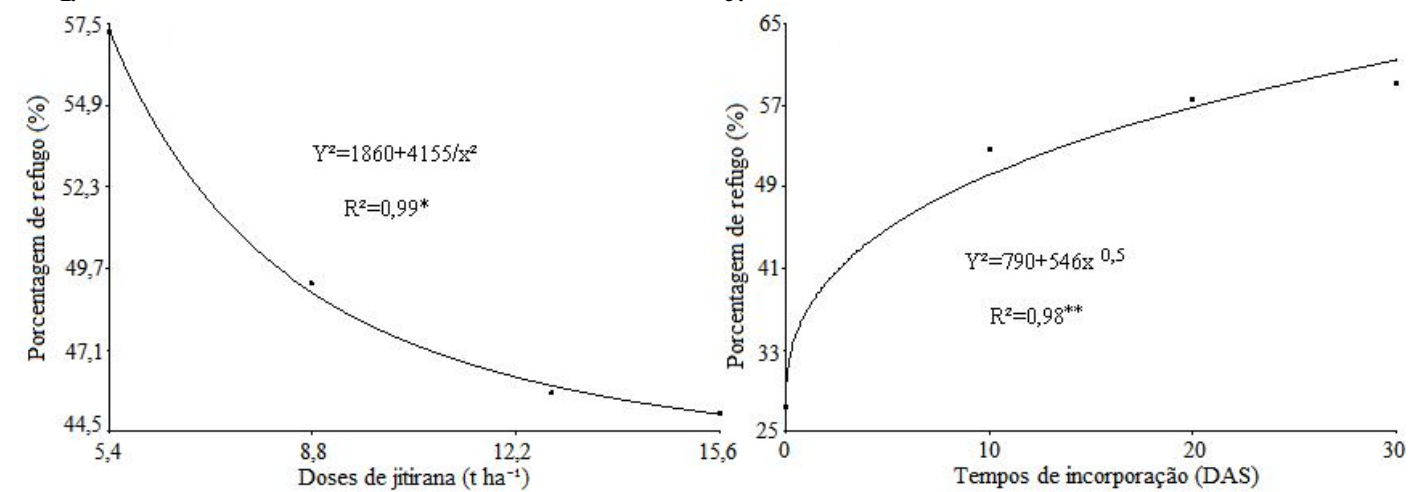

Figura 6. Porcentagem de raízes extra, extra $A$, extra $A A$, graúdas e refugo de beterraba em função de doses de jitirana ( $A$, $C, E, G$ e I) e de seus tempos de incorporação ao solo (B, D , F, H e J) 
incorporadas ao solo notando-se, entretanto, uma porcentagem de raízes extra A de 10,85 e 16,45\% nas doses de jitirana de 5,4 e 15,6 t ha-1 (Figura 6C).

Resposta decrescente na porcentagem de raízes extra A foi observada em função dos tempos de incorporação da jitirana ao solo, com decréscimo da ordem de $11,88 \%$ entre o tempo 0 dia e de 30 dias da incorporação (Figura 6D).

Para a porcentagem de raízes extra AA, não foi possível ajustar nenhuma equação de regressão em função das doses de jitirana incorporadas ao solo, observando-se uma porcentagem de raízes extra AA de beterraba de 3,85 e 7,85\%, nas doses de jitirana de 5,6 e 15,6 t ha-1 (Figura 6E).

Resposta decrescente na porcentagem de raízes extra AA foi observada em função dos tempos de incorporação da jitirana, com decréscimo da ordem de $9,3 \%$ entre o tempo 0 dia e de 30 dias da incorporação (Figura 6F).

Para a porcentagem de raízes graúdas de beterraba não foi possível ajustar qualquer equação de regressão, em função tanto das doses de jitirana incorporadas ao solo como dos tempos de incorporação (Figuras 6G e 6H). Uma porcentagem de raízes graúdas de beterraba entre 0,77 e 2,45\% foi observada nas doses de jitirana de 5,4 e 15,6 t ha-1 (Figura 6G). Em relação aos tempos de incorporação da jitirana a porcentagem de raízes graúdas decresceu até o tempo de 20 dias de incorporação (Figura 6H). Esses baixos valores de raízes graúdas podem ser explicados pelo curto tempo de colheita da cultura neste trabalho (68 dias). De acordo com Horta et al. (2001), o prolongamento da colheita de beterraba aumenta a produtividade comercial de raízes e as cultivares de beterraba podem prolongar seu ciclo e parcelar a colheita em três vezes, para obtenção do seu ponto ideal, ao mesmo tempo (Filgueira, 2003).

Observou-se uma resposta decrescente para porcentagem de raízes refugo em função das doses de jitirana incorporadas ao solo, com porcentagem de raízes refugo de 57,25 e 45,11\% nas doses de jitirana de 5,4 e 15,6 t ha-1 (Figura 6I). Em relação aos tempos de incorporação a porcentagem de raízes refugo cresceu até o tempo de 30 dias da incorporação, atingindo uma porcentagem de 59,37\% no tempo de 30 dias (Figura 6J).

Para altura de plantas, rendimento de massa fresca e seca da parte aérea se observaram, em porcentagem de raízes graúdas, diferenças significativas entre os valores médios da testemunha e dos tratamentos provenientes do fatorial, com os maiores valores registrados na testemunha (cerca de 18,5; 39,9; 27,3 e 200\% superior, respectivamente). Não se observou, porém, qualquer diferença significativa entre os valores médios da testemunha e dos provenientes dos tratamentos do fatorial na produtividade comercial de raízes, rendimento de massa seca das raízes, porcentagem de raízes extra, extra A, extra AA e porcentagem de raízes refugo (Tabela 1).

O custo total de produção de 1 ha de beterraba utilizando-se jitirana como adubo verde, foi estimado para cada quantidade de jitirana incorporada ao solo, sendo observados os seguintes valores: $\mathrm{R} \$ 5.834,54 ; \mathrm{R} \$ 6.338,54 ; \mathrm{R} \$ 6.842,54$ e $\mathrm{R} \$ 7.3467,54$ para as doses de 5,4; 8,8; 12,2 e 15,6 $\mathrm{t} \mathrm{ha}^{-1}$, respectivamente. O custo de utilização de $80 \mathrm{t} \mathrm{ha}^{-1}$ de esterco bovino no cultivo da beterraba foi da ordem de $\mathrm{R} \$ 10.410,54$ (Tabela 2).

Tabela 1. Valores médios da testemunha e das médias dos tratamentos provenientes do fatorial na al tura de plantas (AP), rendimento de massa fresca e massa seca da parte aérea (MFPA, MSPA), produtividade comercial de raízes (PC), rendimento de massa seca de raízes (MSR), porcentagem de raízes extra (E), extra $A(E A)$, extra AA (EAA), graúdas (G) e refugo (R) de beterraba em função de doses de jitirana e de seus tempos da incorporação ao solo

\begin{tabular}{|c|c|c|c|c|c|c|c|c|c|c|}
\hline \multirow{2}{*}{ Tratamento } & \multirow{2}{*}{$\begin{array}{l}\text { AP } \\
(\mathrm{cm})\end{array}$} & MFPA & MSPA & $\overline{P C}$ & MSR & $E$ & EA & EAA & G & $\mathbf{R}$ \\
\hline & & \multicolumn{4}{|c|}{$\left(t\right.$ ha $\left.^{-1}\right)$} & \multicolumn{5}{|c|}{$(\%)$} \\
\hline $\begin{array}{l}\text { Testemunha }{ }^{1} \\
\text { Fatorial }\end{array}$ & $\begin{array}{l}26,9 a^{*} \\
22,7 b\end{array}$ & $\begin{array}{l}11,8 \mathrm{a} \\
8,43 \mathrm{~b}\end{array}$ & $\begin{array}{l}1,4 \mathrm{a} \\
1,1 \mathrm{~b}\end{array}$ & $\begin{array}{l}8,6 a \\
8,3 a\end{array}$ & $\begin{array}{l}1,7 a \\
1,8 a\end{array}$ & $\begin{array}{l}24,2 a \\
28,4 a\end{array}$ & $\begin{array}{l}13,4 a \\
14,6 a\end{array}$ & $\begin{array}{l}7,7 a \\
5,7 a\end{array}$ & $\begin{array}{l}5,4 a \\
1,8 b\end{array}$ & $\begin{array}{l}49,2 a \\
49,3 a\end{array}$ \\
\hline
\end{tabular}

$*$ Médias da testemunha significativamente diferentes da média dos tratamentos provenientes do fatorial pelo teste t de Student, a nível de $5 \%$ de probabilidade
${ }^{1}$ Testemunha esterco bovino

Tabela 2. Indicadores econômicos de renda bruta, renda líquida, taxa de retorno e índice de lucratividade para a cultura da beterraba em função de doses de jitirana e de seus tempos de incorporação ao solo

\begin{tabular}{|c|c|c|c|c|c|c|c|}
\hline \multirow[t]{2}{*}{$\begin{array}{l}\text { Doses de jitirana } \\
\left.\text { (t ha }{ }^{-1}\right)\end{array}$} & \multirow[t]{2}{*}{$\begin{array}{c}\text { Tempos } \\
\text { (DAS) }\end{array}$} & \multirow[t]{2}{*}{$\begin{array}{l}\text { Produção } \\
\left(\text { t ha }^{-1}\right)\end{array}$} & Renda bruta & $\begin{array}{l}\text { Custo de } \\
\text { produção }\end{array}$ & Renda líquida & $\begin{array}{l}\text { Taxa de } \\
\text { retorno } \\
\end{array}$ & \multirow{2}{*}{$\begin{array}{c}\text { Índice de } \\
\text { lucratividade } \\
(\%)\end{array}$} \\
\hline & & & \multicolumn{4}{|c|}{$\left(R \$ h^{-1}\right)$} & \\
\hline 5,4 & 0 & 12,11 & $18.165,00$ & $5.834,54$ & $12.330,46$ & 3,11 & 67,9 \\
\hline 5,4 & 10 & 5,40 & $8.100,00$ & $5.834,54$ & $2.265,46$ & 1,39 & 27,9 \\
\hline 5,4 & 20 & 3,22 & $4.830,00$ & $5.834,54$ & $-1.004,54$ & 0,82 & $-20,8$ \\
\hline 5,4 & 30 & 2,75 & $4.125,00$ & $5.834,54$ & $-1.709,54$ & 0,70 & $-41,4$ \\
\hline 8,8 & 0 & 14,00 & $21.000,00$ & $6.338,54$ & $14.661,46$ & 3,31 & 69,8 \\
\hline 8,8 & 10 & 7,35 & $11.025,00$ & $6.338,54$ & $4.686,46$ & 1,74 & 42,5 \\
\hline 8,8 & 20 & 6,86 & $10.290,00$ & $6.338,54$ & $3.951,46$ & 1,63 & 38,4 \\
\hline 8,8 & 30 & 5,00 & $7.500,00$ & $6.338,54$ & $1.161,46$ & 1,10 & 15,5 \\
\hline 12,2 & 0 & 15,62 & $23.430,00$ & $6.842,54$ & $16.587,46$ & 3,42 & 70,8 \\
\hline 12,2 & 10 & 9,87 & $14.805,00$ & $6.842,54$ & $7.962,46$ & 2,16 & 53,8 \\
\hline 12,2 & 20 & 5,32 & $7.980,00$ & $6.842,54$ & $1.137,46$ & 1,16 & 14,2 \\
\hline 12,2 & 30 & 5,84 & $8.760,00$ & $6.842,54$ & $1.917,46$ & 1,20 & 21,9 \\
\hline 15,6 & 0 & 16,96 & $25.440,00$ & $7.346,54$ & $18.093,46$ & 3,46 & 71,1 \\
\hline 15,6 & 20 & 6,78 & $10.170,00$ & $7.346,54$ & $2.823,46$ & 1,38 & 27,7 \\
\hline 15,6 & 30 & 6,84 & $10.260,00$ & $7.346,54$ & $2.913,46$ & 1,39 & 28,4 \\
\hline Esterco bovino & $80\left(t^{h} a^{-1}\right)$ & 9,41 & $14.115,00$ & $10.410,54$ & $3.704,46$ & 1,35 & 26,3 \\
\hline
\end{tabular}


Observaram-se as maiores rendas e eficiências monetárias na maior dose de jitirana incorporada de $15,6 \mathrm{t} \mathrm{ha}^{-1}$ e no tempo de 0 dia após a semeadura, com valores estimados de renda bruta de $\mathrm{R} \$ 25.440,00$, de renda líquida de $\mathrm{R} \$ 18.093,46$, taxa de retorno de $\mathrm{R} \$ 3,46$ e índice de lucratividade de $71,1 \%$. Por outro lado, as menores rendas e eficiências monetárias foram constatadas na menor dose de $5,4 \mathrm{t} \mathrm{ha}^{-1}$ no tempo 30 dias da incorporação da jitirana após a semeadura da beterraba, registrando-se renda bruta de $\mathrm{R} \$ 4.125,00$, renda líquida de $\mathrm{R} \$-1.709,54$, taxa de retorno de $\mathrm{R} \$ 0,70$ e índice de lucratividade de $-41,4 \%$, comparativamente ao uso do esterco bovino, que também apresentou resultados inferiores para taxa de retorno de $\mathrm{R} \$ 1,35$ e índice de lucratividade de 26,3\%. Desta forma e se utilizando a jitirana como adubo verde incorporada ao solo no tempo 0 dia na dose de $15,6 \mathrm{tha}^{-1}$, o produtor pode obter 3,46 reais de retorno a cada real investido (Tabela 2).

A renda bruta e a líquida variaram de $R \$ 4.125,00$ a $R \$$ 25.440,00 e de $\mathrm{R} \$-1.709,59$ a $\mathrm{R} \$ 18.093,46$ respectivamente, com as doses de jitirana aplicadas ao solo e seus tempos de incorporação da jitirana. A taxa de retorno e o índice de lucratividade variaram de 0,70 a $\mathrm{R} \$ 3,46$ e de $-41,4$ a 71,1\%, respectivamente, com as doses de jitirana e seus tempos de incorporação. Os maiores valores desses indicadores foram obtidos na dose de $15,6 \mathrm{t} \mathrm{ha}^{-1}$ no tempo 0 dia da incorporação da jitirana ao solo (Tabela 2).

De modo geral, a renda bruta, renda líquida, taxa de retorno e o índice de lucratividade com uso da dose de 15,6 t ha-1 de jitirana no tempo de 0 dia da incorporação da jitirana ao solo, foram superiores aos do tratamento com esterco bovino.

\section{Conclusões}

1. A melhor performance produtiva da beterraba foi obtida na dose de 15,6 tha ${ }^{-1}$ de jitirana incorporada ao solo, no tempo 0 dia.

2. Os indicadores econômicos na dose de $15,6 \mathrm{t} \mathrm{ha}^{-1}$ no tempo de 0 dia foram superiores aos obtidos com o uso de $80 \mathrm{t} \mathrm{ha}^{-1} \mathrm{de}$ esterco bovino.

3. O cultivo da beterraba é viável agroeconomicamente com o uso da jitirana como adubo verde.

\section{LITERATURA CITADA}

Alcântara, F. A. de; Ferreira Neto, A. E.; Paula, M. B. de; Mesquita, H. A. de; Muniz, J. A. Adubação verde na recuperação da fertilidade de um latossolo vermelho escuroldegradado. Pesquisa Agropecuária Brasileira, v.35, p.277-288, 2000.

Almeida, M. M. T. B.; Lixa, A. T.; Silva, E. E. da; Azevedo, P. H. S.; De-Polli H.; Ribeiro, R. L. D. Fertilizantes de leguminosas como fontes alternativas de nitrogênio para produção orgânica de alface. Pesquisa Agropecuária Brasileira, v.43, p.675-682, 2008.

Alves, A. U.; Prado, R. M.; Gondim, A. R. O.; Fonseca, I. M.; Cecílio Filho, A. B. Desenvolvimento e estado nutricional da beterraba em função da omissão de nutrientes. Horticultura Brasileira, v.26, p.292-295, 2008.
Alves, S. M. C.; Abboud, A. C. S.; Ribeiro. R. L. D.; Almeida, D. L. Balanço do nitrogênio e fósforo em solo com cultivo orgânico de hortaliças após a incorporação de biomassa de guandu. Pesquisa Agropecuária Brasileira, v.39, p.1111-1117, 2004.

Aquino, L. A.; Puiatti, M.; Pereira, P. R. G.; Pereira, F. H. F.; Ladeira, I. R.; Castro, M. R. S. Produtividade, qualidade e estado nutricional da beterraba de mesa em função de doses de nitrogênio. Horticultura Brasileira, v.24, p.199-203, 2006.

Calegari, A. Rotação de culturas e uso de plantas de cobertura. Agroecologia, v.2, p.14-19, 2002.

Carmo Filho, F. do; Oliveira, O. F. de. Mossoró: Um município do semi-árido nordestino. Mossoró: Fundação Guimarães Duque/ESAM, 1989. 62p. Coleção Mossoroense, Série B. n.682

Castro, C. M. de; Alves, B. J. R.; Almeida, D. L. de; Ribeiro, R. L. D. de. Adubação verde como fonte de nitrogênio para a cultura da berinjela em sistema orgânico. Pesquisa Agropecuária Brasileira, v.39, p.779-785, 2004.

EMBRAPA - Empresa Brasileira de Pesquisa Agropecuária. Centro Nacional de Pesquisa de solos. Sistema brasileiro de classificação de solos. 2.ed. Rio de Janeiro: EMBRAPA, 2006. 306p.

Fageria, N. K.; Santos, A. B. Resposta do arroz irrigado à adubação verde e química no Estado de Tocantins. Revista Brasileira Engenharia Agrícola e Ambiental, v.11, p.387-392, 2007.

Falcão J. I. A. Contribuição ao estudo das espécies brasileiras do gênero Merremia dennst. Rodriguesia, v.16/17, p.105114, 1954.

Favero, C.; Jucksch, I.; Costa, L. M.; Alvarenga, R. C.; Neves, J. C. L. Crescimento e acúmulo de nutrientes por plantas espontâneas e por leguminosas utilizadas para adubação verde. Revista Brasileira de Ciência do Solo, v.24, p.171-177, 2000.

Ferreira, D. F. Sistema SISVAR para análises estatísticas: Manual de orientação. Lavras: Universidade Federal de Lavras/ Departamento de Ciências Exatas, 2000. 37p.

Filgueira, F. A. R. Novo manual de olericultura: Agrotecnologia moderna na produção e comercialização de hortaliças, Viçosa: UFV, 2003. 412p.

Fontanétti, A.; Carvalho, G. J. de; Morais, A. R. de; Almeida, K. de; Duarte, W. F. Adubação verde no controle de plantas invasoras nas culturas de alface americana e de repolho. Ciência e Agrotecnologia, v.28, p.967- 973, 2004.

Grangeiro, L. C.; Negreiros, M. Z. de; Souza, B. S. de; Azevedo, P. E. de; Oliveira, S. L. de, Medeiros, M. A. de. Acúmulo e exportação de nutrientes em beterraba. Ciência e Agrotecnologia, v.31, p.267-273, 2007.

Horta, A. C. S.; Santos H. S.; Scapim C. A.; Callegari O. Relação entre produção de beterraba, Beta vulgaris var. conditiva, e diferentes métodos de plantio. Acta Scientiarum, v.23, p.1123-1129, 2001.

Jandel Scientific. Table curve: Curve fitting software. Corte Madera: Jandel Scientific, 1991. 280p.

Khatouniam, C. A. Problemas usuais para o manejo sustentável de agrossistemas no Centro-Sul do Brasil. Ciências e Tecnologia, v.24, 2001. 
Linhares, P. C. F.; Leite de Lima, G. K.; Madalena. J. A. da S.; Maracajá, P. B.; Fernandes, P. L. de O. Adição de jitirana ao solo no desempenho de rúcula cv. Folha Larga. Revista Caatinga, v.21, p.89-94, 2008.

Linhares, P. C. F.; Silva, L. M.; Silva, J. S.; Holanda, A. K.; Silva, U. L. Influência da jitirana em cobertura como adubação verde sobre o desempenho agronômico da alface. Caatinga, v.22, p.65-69, 2009 b.

Linhares, P. C. F.; Silva, L. M.; Silva, U. L.; Silva, J. S.; Holanda, A. $\mathrm{K}$. Velocidade e tempo de decomposição da jitirana incorporada na cultura do rabanete. Caatinga, v.22, p.206-210, 2009a.

Marques, L. F; Medeiros, D. C.; Coutinho, O. L.; Marques, L. F.; Medeiros, C. B.; Vale, L. S. Produção e qualidade da beterraba em função da adubação com esterco bovino. Revista Brasileira de Agroecologia, v.5, p.24-31, 2010.

Nascimento, A. F.; Mattos, J. L. S. Benefícios com a utilização de adubos verdes. Revista Brasileira de Agroecologia, v.2, p.41-55, 2007.
Oliveira, M. K. T. Viabilidade agroeconômica da cenoura adubada com jitirana. Mossoró: UFERSA, 2009. 88p. Dissertação Mestrado

Resende, G. M. de; Cordeiro, G. G. Uso da água salina e condicionador de solo na produtividade de beterraba e cenoura no semi-árido do submédio São Francisco. Petrolina: Embrapa Semi-Árido. 2007. 4p. Comunicado Técnico, 128

Silveira, P. M.; Braz, A. J. B. P.; Kliemann, H. J.; Zimmermann, F. J. P. Adubação nitrogenada no feijoeiro cultivado sob plantio direto em sucessão de culturas. Pesquisa Agropecuária Brasileira, v.40, p.377-38, 2005.

Souza, R. J. de; Fontanetti, A.; Fiorini, C. V. A.; Almeida, K. de. Cultura da beterraba: Cultivo convencional e cultivo orgânico. Lavras: UFLA, 2003. 37p.

Trani, P. E.; Cantarella, H.; Tivelli, S. W. Produtividade de beterraba em função de doses de sulfato de amônio em cobertura. Horticultura Brasileira, v.23, p.726-730, 2005. 